\title{
Aproximación crítica a los derechos humanos desde las perspectivas liberal, conservadora y neoliberal
}

\author{
Marco Cortez \\ Universidad de La Serena
}

Resumen: En marco de una aproximación crítica al tema de los derechos humanos, relacionada con los fundamentos que constituyen su existencia en tanto posibilidad, el presente trabajo analiza tres perspectivas filosóficas relacionadas con dicha temática: el liberalismo, el conservadurismo y el neoliberalismo. El trabajo examina así los orígenes históricos de cada una de estas corrientes, sus principales representantes, y las posibles coincidencias y diferencias entre estas. Se espera demostrar que, en su análisis de los derechos humanos, ninguna de las tres tradiciones escogidas ha conseguido superar la dimensión jurídica, ignorando casi del todo las dimensiones ético-normativa y utópica.

Palabras clave: derechos humanos; crítica; liberalismo; conservadurismo; neoliberalismo

\begin{abstract}
Critical approach to human rights from the liberal, conservative and neoliberal perspective". Within the framework of a critical approach to the topic of human rights, related to the foundations that constitute its existence as a possibility, this paper analyzes three philosophical perspectives related to this topic: liberalism, conservatism and neoliberalism. The work thus examines the historical origins of each of these currents, their main representatives, and the possible coincidences and differences between them. It is expected to demonstrate that, in its analysis of human rights, none of the three chosen traditions has managed to overcome the legal dimension, ignoring almost completely the ethical-normative and utopian dimensions perspectives.
\end{abstract}

Keywords: human rights; review; liberalism; conservatism; neoliberalism 


\section{Introducción}

Los derechos humanos han sido caracterizados de múltiples maneras. Ante todo, como un cuerpo legislativo que pretende situarse por encima de los Estados en tanto orden moral, cuyos imperativos éticos pretenden validez universal y reconocimiento por parte de toda la humanidad. Igualmente, los derechos humanos han sido objeto de distintas criticas provenientes de distintas tradiciones: desde el liberalismo conservador, pasando por el conservadurismo, hasta el marxismo ${ }^{1}$.

Este trabajo se centrará en examinar las principales críticas formuladas a los derechos humanos, tanto desde la tradición del liberalismo como desde el pensamiento conservador. Este se dividirá en tres grandes secciones. La primera sección está dirigida a presentar los antecedentes históricos y filosóficos del liberalismo, dando cuenta de las distintas corrientes que dicen estar inspiradas en este pensamiento. La segunda sección examinará el pensamiento conservador y se detendrá en la figura de Edmund Burke por ser el primer autor en proponer una crítica sistemática de los derechos humanos. Finalmente, la tercera sección se centrará en el neoliberalismo: se analizarán sus orígenes históricos y sus principales representantes, así como la crítica que desde esta corriente se ha ido formulando a la doctrina de los derechos humanos, concretamente, a la idea de justicia social.

En el presente trabajo, los derechos humanos se entenderán entonces como un cuerpo legislativo, como un conjunto de normas éticas que aspiran a ser reconocidas como universalmente válidas y enmarcadas, finalmente, bajo un horizonte utópico. Las principales críticas que se han formulado a los derechos humanos se perfilan en torno a la primera dimensión y en parte también a la segunda, dejando de lado el carácter utópico de estos últimos. Si bien se reconoce la importancia de las dos primeras, este trabajo pretende rescatar la tercera dimensión, a menudo olvidada por las distintas tradiciones filosóficas que han analizado el problema. Esta última representa un desafio, dado que

\footnotetext{
1 Las principales críticas que se han formulado a los derechos humanos proceden de tres corrientes filosóficas, las cuales van desde la tradición conservadora, seguida por el neoliberalismo, hasta llegar al marxismo. Cf., Bariffi, F.J., "Negación de los Derechos Humanos: el pensamiento conservador de Edmund Burke”, en: Revista Telemática de Filosofía del Derecho, 6 (2003), pp. 265-278.
} 
impide, por una parte, la clausura de la discusión en torno a cualquiera de los otros dos planos y, al mismo tiempo, introduce un sentido de esperanza, "cuasi teologal", que permite albergar la idea de que el mundo puede cambiar². Además, mientras las otras dos dimensiones sancionan de algún modo lo ya establecido, mirando siempre hacia el pasado, o bien, consagrando el presente como algo estable y definitivo, esta apunta en dirección a un "mañana", hacia un "futuro", que, por serlo, no existe todavia, pero que a pesar de todo encierra una promesa de que las cosas pueden mejorar.

Quedará para un próximo trabajo el examen pormenorizado de la crítica que desde el marxismo se efectúa a los derechos humanos, la cual complementará lo expuesto en el presente trabajo.

\section{Principales antecedentes históricos y filosóficos del liberalismo}

El liberalismo es un movimiento político y filosófico que surge inicialmente en Europa, entre los siglos XVII y XVIII, dentro de un contexto histórico dominado por el absolutismo monárquico heredado del viejo orden feudal ${ }^{3}$. En términos generales, el liberalismo expresa la visión del mundo de una nueva clase social que en esos momentos estaba emergiendo y que rápidamente ascenderá al poder como consecuencia directa de la Revolución francesa (17891799): la burguesía. Este primer antecedente es importante para comprender las principales características que presenta el liberalismo clásico, sobre todo en lo que se refiere a su posición frente al Estado y a la concepción que tiene de los derechos humanos ${ }^{4}$. Este liberalismo se propuso originalmente tres cosas:

A) Limitar los poderes y funciones del Estado.

B) Promover una defensa de los derechos humanos mediante el iusnaturalismo.

C) Organizar una sociedad libre inspirada en la defensa de la propiedad privada.

\footnotetext{
2 Este carácter cuasi teologal, con el que a menudo se revisten los derechos humanos, es lo que los hace seductores, pero que, al mismo tiempo, constituye su principal debilidad, se oculta la imposibilidad de los mismos, manteniendo, sin embargo, la promesa de que las cosas pueden mejorar. Cf., Barrantes, M.P., El fundamento ideológico de los derechos humanos. Crítica ideológica al discurso de la Corte Interamericana de Derechos Humanos, Tesis (Derecho), San José de Costa Rica: Universidad de San José de Costa Rica, 2008.

3 Para los antecedentes históricos que rodean el surgimiento del liberalismo, cf., Hobsbawm, E., La era de la revolución, México D.F.: Fondo de Cultura Económica, 2012.

4 Para una caracterización del liberalismo clásico, así como de las principales corrientes que se derivan de este, $c f$., Larrain, J., ¿América Latina moderna? Globalización e identidad, Santiago de Chile: Lom Editores, 2005.
} 
Entre sus fundamentos filosóficos se encuentran el individualismo, el utilitarismo y la defensa de un racionalismo pretendidamente científico $^{5}$. El liberalismo se apoya en una antropologia que concibe al hombre como un ser esencialmente egoísta, violento, codicioso, preocupado tan solo de sí mismo e incapaz de pensar en nadie más que no sea él ${ }^{6}$. Dado que un ser semejante dificilmente respetará la vida y las posesiones de sus semejantes, a no ser que se interponga entre él y sus inclinaciones naturales un poder que lo obligue a ello, el liberalismo abogará por la necesidad de establecer un orden que, protegiendo la vida, la libertad y la propiedad por medio de la ley emanada del contrato social, haga posible la defensa de las libertades individuales frente al poder del Estado y al intervencionismo de los gobiernos. Locke lo expresa de la siguiente manera: "el Estado es, a mi parecer, una sociedad de hombres constituida únicamente para preservar y promocionar sus bienes civiles. Lo que llamo bienes civiles son la vida, la libertad, la salud corporal, el estar libres de dolor y la posesión de cosas externas, tales como dinero, tierras, casas, muebles y otras semejantes"7.

El liberalismo clásico parte de un supuesto "estado de naturaleza", anterior a la sociedad civil y a la constitución del Estado, en el cual, en ausencia de leyes que garanticen la protección de la vida y de la propiedad, cada hombre debe atender a su propia conservación. Dado que en esta condición los hombres se ven forzados a vivir bajo una permanente zozobra, pues en ausencia de leyes nadie se encuentra a salvo de no experimentar algún tipo de violencia de parte de sus semejantes, se hace necesario que, mediante un pacto originario que recibe el nombre de "contrato social", cada hombre renuncie a una parte de su "libertad natural" al comprometerse desde ese momento en adelante a respetar la vida y las posesiones de sus semejantes y gozando a su vez del amparo que le brindan las leyes emanadas del contrato social. Como lo señala el propio Rousseau, el propósito de este contrato social no es otro que "hallar una forma de asociación que defienda y proteja de toda la fuerza común a la persona y a los bienes de cada asociado, y en virtud de la cual, al unirse cada uno a todos, no obedezca más que a sí mismo y quede tan libre como antes"8.

\footnotetext{
5 Para una caracterización de los fundamentos filosóficos del liberalismo, puede revisarse la obra de Mises, L., Liberalismo. La tradición clásica, Madrid: Unión Editorial, 2011.

6 Para una buena caracterización de esta antropología de la que arranca el pensamiento liberal, puede revisarse la obra de García, C., La revolución mundial del capitalismo, Buenos Aires: El Ateneo, 1988.

7 Locke, J., Ensayo y carta sobre la tolerancia, Madrid: Alianza Editorial, 2011, p. 66.

8 Rousseau, J.J., El contrato social, Buenos Aires: Gradifco, 2007, p. 23.
} 
Desde un comienzo, el liberalismo buscó establecer ciertos límites en cuanto a la acción del Estado y a los poderes que legítimamente podía detentar. Estos límites han quedado fijados por la misma naturaleza humana. De esta manera, el liberalismo reconoce la existencia de algunos derechos fundamentales que resultan anteriores a la constitución del Estado y que de ningún modo pueden ser transgredidos por parte de los gobernantes como representantes del Estado sin que la autoridad de la que se encuentran revestidos se convierta en tiránica, justificando así el derecho de los pueblos a la legítima rebelión ${ }^{9}$. Estos derechos se consideran, por lo mismo, como "naturales", es decir, su origen se encuentra en la naturaleza humana y de ninguna manera puede la autoridad desconocerlos o conculcarlos ${ }^{10}$. Locke parte en su concepción de los derechos naturales, del "estado de naturaleza", caracterizado por la obligación moral que tienen todos los individuos de observar y respetar la "ley natural", la cual, a juicio de este, “...enseña a cuantos seres humanos quieren consultarla que, siendo iguales e independientes, nadie debe dañar a otro en su vida, salud, libertad o posesiones"11.

Estos derechos fundamentales se reducen a tres: el derecho a la vida, a la libertad y a la propiedad. Para el liberalismo, el derecho a la libertad tiene por fundamento el derecho a la propiedad, dado que sin propiedad no hay libertad ${ }^{12}$. En este último punto concuerdan las distintas corrientes que manifiestan inspirarse en el pensamiento liberal. En cuanto al derecho a la vida, este se concibe como el primero de todos los derechos, dado que supone establecer un límite definitivo en lo tocante a los poderes y funciones que puede asumir el Estado,

\footnotetext{
9 Esta idea se encuentra esbozada en la obra de Locke, J., Segundo tratado del gobierno civil, Madrid: Aguilar, 2010. Locke toma esta idea de Richard Hooker, un teólogo de la Iglesia Anglicana, famoso por sus ideas acerca de la tolerancia, quien a su vez la recibe de Francisco de Vittoria y de Santo Tomás de Aquino.

${ }^{10}$ Puede revisarse la obra de Bobbio, N., Liberalismo y democracia, México D.F., Fondo de Cultura Económica, 2010, donde se presenta un resumen de esta idea de los derechos naturales que se encuentra en la base del liberalismo clásico.

${ }^{11}$ Locke, J., Segundo tratado del gobierno civil, p. 22. Esta idea de la ley natural fue ampliamente desarrollada por la tradición escolástica, en especial por Santo Tomás de Aquino. Sin embargo, el modo en que el filósofo inglés trata esta cuestión es diferente de la manera en que la trató la tradición escolástica. Para Santo Tomás, por ejemplo, el hombre es un ser naturalmente social, mientras que la tradición del liberalismo arranca de un supuesto estado de naturaleza anterior a la sociedad y al Estado, que poco tiene que ver con lo que enseña la tradición anterior a Locke y al liberalismo.

${ }^{12}$ Véase, Bobbio, N., Liberalismo y democracia, en especial los capítulos III y IV, donde se trata específicamente acerca de los límites del poder del Estado y de cuando es necesario ir en contra de este poder.
} 
el que para ciertas concepciones liberales, como el "libertarismo", entre otras, solo puede justificarse bajo la forma de un "Estado mínimo"13.

El liberalismo presenta una concepción negativa de la libertad, dado que alguien es libre cuando no encuentra obstáculos para realizar su voluntad. Como lo reconoce el propio Hobbes: "por libertad se entiende, de acuerdo con el sentido propio de la palabra, la ausencia de impedimentos externos, impedimentos que con frecuencia reducen parte del poder que un hombre tiene de hacer lo que quiere"14.

De esta manera, la concepción liberal se distingue claramente de otras concepciones como el socialismo, por mencionar solo un ejemplo, porque coloca el acento en el carácter estrictamente individual de la libertad, despreocupándose por completo de la desigualdad que se derivaría de lo anterior, por considerarla como algo natural, inherente, por lo tanto, a la misma "condición humana", la cual no consiente ser modificada ${ }^{15}$. El liberalismo propone una concepción negativa de la libertad, asumiendo que las personas son libres cuando no encuentran ningún obstáculo que se interponga entre ellas y el logro de sus objetivos. De este modo, la desigualdad que surge de la diferencia de acceso en cuanto a los recursos y medios de vida de que disponen las personas, especialmente en una sociedad basada en la propiedad privada sobre los medios de producción, es ignorada o, en su defecto, acaba atribuyéndosele a la misma naturaleza humana ${ }^{16}$.

Partiendo de esta concepción negativa de la libertad, el liberalismo va a defender, como complemento de su antropología basada en el individualismo, una ética utilitarista según la cual los hombres buscan naturalmente el placer y huyen del dolor. En esta doctrina, el placer se identificará con la felicidad y esta, a su vez, se relacionará de modo directo con el bien, por lo que necesariamente el dolor se asociará con la infelicidad y con el mal.

El utilitarismo descansa sobre la utilidad, que John Stuart Mill enuncia del siguiente modo: "el credo que acepta la Utilidad o Principio de la Mayor Felicidad como fundamento de la moral, sostiene que las acciones son justas

\footnotetext{
${ }^{13}$ Para esta idea del Estado mínimo puede revisarse la obra de Nozick, R., Anarquía, Estado y utopía, México: Fondo de Cultura Económica, 2012.

${ }^{14}$ Hobbes, Leviatán, México: Fondo de Cultura Económica, 2010, p. 106.

15 Esta justificación de la desigualdad se encuentra especialmente desarrollada en Mises, L., Liberalismo. La tradición clásica.

${ }^{16}$ Cf., Kaiser, A., La tiranía de la igualdad, Santiago de Chile: El Mercurio Ediciones, 2015.
} 
en la proporción con que tienden a promover la felicidad; e injustas en cuanto tienden a producir lo contrario de la felicidad"17.

Sin embargo, el utilitarismo entrará desde un comienzo en conflicto directo con la doctrina de los derechos naturales del hombre, generándose en este punto la primera ruptura que va a experimentar el pensamiento liberal, la que posteriormente desembocará en el surgimiento de un liberalismo conservador y, con el correr del tiempo, también del neoliberalismo, los cuales, en apariencia entran en conflicto con aquellas cosas que había defendido originariamente el liberalismo clásico, como la democracia y los derechos humanos.

La razón para todo esto debemos buscarla en el pensamiento de Bentham, considerado el padre de la corriente utilitarista pues, a juicio de este autor, "no existe nada semejante a los derechos naturales, nada similar a los derechos anteriores a las instituciones de gobierno, nada semejante a los derechos naturales opuestos o en contradicción con los legales"18.

Por eso, el deber de los gobiernos no es defender unos hipotéticos "derechos naturales", sino atender a la felicidad del mayor número posible de ciudadanos. En contraste, el liberalismo clásico deseaba limitar los poderes y funciones del Estado al partir de una concepción iusnaturalista según la cual al hombre le asistirian ciertos derechos que se derivan de la propia naturaleza humana, por lo que estos derechos serían anteriores al Estado. De este modo, si la autoridad atentaba contra los mismos se volvía tiránica, estos podían rebelarse legitimamente ante esta injusticia ${ }^{19}$. Dado que el iusnaturalismo es una doctrina jurídica política inspirada en la filosofia griega y en la escolástica, el nuevo liberalismo se desentiende de esta concepción por considerarla poco científica, proponiendo en su lugar una nueva visión que pretende estar avalada por la ciencia ${ }^{20}$. Esta concepción recibe el nombre de "racionalismo" $\mathrm{y}$, a diferencia del sentido filosófico que inspiraba al viejo liberalismo, este nuevo racionalismo pretende ser científico. Su premisa fundamental es que el hombre debe actuar racionalmente, es decir, que debe basar su acción en un cálculo racional de expectativas que le permita, una vez efectuado el cálculo, establecer los costos y beneficios que se derivan de adoptar una decisión u

\footnotetext{
${ }_{17}$ Mill, J., Sobre la libertad. El utilitarismo, Buenos Aires: Orbis, 1980, p. 139.

18 Bentham, J., Sofismas anárquicos, citado en: Bobbio, N., Liberalismo y democracia, p. 69.

19 Véase sobre esta materia, la obra anteriormente citada de Locke, J., Segundo tratado del gobierno civil.

${ }^{20}$ Para un tratamiento más acabado de este racionalismo científico, véase la obra de Mises, L., Liberalismo. La tradición clásica.
} 
otra, escogiendo aquella que implica un mayor beneficio y un menor costo ${ }^{21}$ Como bien lo hace notar $\mathrm{Mises}^{22}$, no significa que se espere que el hombre actúe siempre racionalmente, sino que se pretende que así debería conducirse ante cualquier circunstancia, en la medida en que sus acciones se basan en el cálculo racional de expectativas.

Un ejemplo claro lo constituye la esclavitud. Para el liberalismo clásico, que unos hombres sean reducidos por otros hombres a la condición de esclavos atenta contra el derecho natural a la libertad, entendida esta en el más amplio sentido de la palabra: como libertad de movimiento, pensamiento, expresión, asociación, entre otras cosas. Dado que a ningún hombre le está permitido arrebatarle a otro aquello que le pertenece por derecho propio, como lo es la libertad, no queda entonces más alternativa que concluir que el origen de la esclavitud se encuentra siempre en la guerra, no existiendo otro fundamento para aquella que la tiranía, la que jamás podrá convertirse en un derecho por ser lo anterior contrario a la razón. Como bien lo expresa Rousseau: "renunciar a la libertad es renunciar a la cualidad de hombre, a los derechos de la humanidad, incluso a sus deberes"23. Sin embargo, para el neoliberalismo, heredero en esto del liberalismo conservador, no es en la doctrina de los derechos naturales donde deben buscarse los argumentos para oponerse a la esclavitud, sino de nuevo en la ciencia. El trabajo es más productivo cuando se ejecuta libremente, sin la presencia de alguna forma de coacción, como sucedía en la Antigüedad, cuando existía la esclavitud directa ${ }^{24}$. De este modo, los motivos por los cuales el neoliberal se opone al trabajo forzado, o también a la tiranía, no se deben a una cuestión de humanitarismo en el primero de los casos ni tampoco a su irrestricto respeto por la democracia en el segundo, sino más bien a la necesidad de cautelar el correcto funcionamiento de un orden social que descansa en la protección de la propiedad privada y de las libertades individuales a ella asociadas ${ }^{25}$.

A partir de Bentham, el liberalismo y el utilitarismo caminarán juntos, propiciando a su vez la separación entre el viejo liberalismo clásico, aferrado a una concepción iusnaturalista, y el nuevo liberalismo, que se pretende basado en la ciencia. Como lo reconoce Bobbio: "para el pensamiento liberal el paso

${ }^{21} C f$., Friedman, M., Libertad de elegir, Buenos Aires: Orbis, 1983.

22 Cf., Mises, L., La acción humana, Madrid: Unión Editorial, 1986.

23 Rousseau, J.J., El contrato social, pp. 18-19.

${ }^{24}$ Para un desarrollo más en profundidad de este argumento, revísese la obra de Mises, L., Liberalismo. La tradición clásica.

25 Para un desarrollo de esta última idea, cf., Mises, L., La acción humana. 
del iusnaturalismo al utilitarismo señala una verdadera y propia crisis de sus fundamentos, que llegará hasta el renovado debate sobre los derechos del hombre de estos últimos años"26.

La consecuencia inmediata de esta ruptura que experimenta el pensamiento liberal será el surgimiento de dos corrientes opuestas, cada una de las cuales se declara a su vez como "liberal", con notables diferencias tanto en el modo en que conciben la democracia como en la relación que establecen entre libertad e igualdad (por señalar solo algunos puntos en disputa) ${ }^{27}$. Estas dos formas de liberalismo son

A) Un liberalismo más conservador ${ }^{28}$ que -tomando distancia de la efervescencia revolucionaria a la que dará origen la Revolución francesa (1789-1799), primero en Europa y después, en América, con las guerras de independencia, inspiradas en aquella- desconfia de la democracia e intenta, por su parte, salvaguardar las conquistas del liberalismo clásico, especialmente en lo que se relaciona con la propiedad y las libertades individuales.

B) Un liberalismo más social ${ }^{29}$ que, a diferencia del primero, siente aprecio por la democracia, e intenta llevar a la práctica el ideal de igualdad promovido por la Revolución francesa, cuestión que lo conducirá a diferenciarse del liberalismo conservador, dado que no cree que la igualdad sea incompatible con la libertad, como piensa el primero, y posteriormente, también el neoliberalismo, heredero espiritual del liberalismo conservador.

En lo que sigue a continuación, se intentará mostrar como las críticas que se formulan desde el pensamiento conservador, así como desde el neoliberalismo, a los derechos humanos, comparten más cosas en común de lo que a simple vista pudiese parecer, tanto entre sí como también con el liberalismo clásico.

\section{Critica de los derechos humanos desde la perspectiva conservadora}

En este trabajo se entenderá por "conservadurismo" una corriente de pensamiento político que surge en el contexto de la Revolución francesa, en

\footnotetext{
26 Bobbio, N., Liberalismo y democracia, p. 70.

27 Para una caracterización de las diferencias que encontramos en el pensamiento liberal, $c f$., Larrain, J., ¿América Latina moderna? Globalización e identidad.

28 Entre los principales representantes de este liberalismo conservador, se encuentran autores como Edmund Burke, cuyo pensamiento se examinará con algún detalle en la segunda sección del presente trabajo, y Alexis de Tocqueville.

${ }^{29}$ Entre los representantes de este liberalismo social, se encuentran autores como John Maynard Keynes, cuyo pensamiento económico dominó la escena durante buena parte del siglo XX, y John Dewey.
} 
medio de la gran agitación política y social que significó dicho acontecimiento histórico tanto para Europa como para el resto del mundo. Entre los principales representantes de esta corriente encontramos a autores como Louis de Bonald (1754-1840) y Joseph de Maistre (1753-1821) en Francia; a Edmund Burke (1729-1797) en Inglaterra; y a Juan Donoso y Cortés (1809-1853) en España. Lo que une a todos estos autores es el rechazo de la Revolución francesa, por una parte, y la defensa apasionada del Antiguo Régimen, por la otra. Pero será Burke, entre todos ellos, quien concite la mayor atención por haber sido el primero en denunciar públicamente el terror sangriento que trajo consigo la marea revolucionaria que le puso punto final al Antiguo Régimen. Destaca también por ser el primer autor en elaborar una crítica sistemática de la doctrina de los derechos humanos, anticipándose en cierto modo a la crítica que posteriormente se hará de estos últimos, comenzando por el pensamiento conservador, seguido por el neoliberalismo hasta terminar con el marxismo.

El fundamento filosófico sobre el que descansa la denuncia que hará el pensamiento conservador a la sociedad que emerge directamente de la Revolución francesa descansa en la existencia previa de un "orden natural", el cual no ha sido obra humana, y al que cualquier sociedad debe someterse si no desea verse condenada a un desastre por haber querido desafiar a la naturaleza ${ }^{30}$. Por "naturaleza" se entiende, por una parte, el conjunto de todas las leyes que gobiernan a la totalidad de lo que existe; por otra, a las cualidades que hacen de un ser lo que este se encuentra destinado a ser, es y ha sido desde un comienzo ${ }^{31}$. La primera crítica que se hace de la Revolución francesa será, pues, a sus fundamentos filosóficos e ideológicos, especialmente a la figura de Rousseau y a su doctrina del contrato social, a la que se tildará abiertamente de ficción ${ }^{32}$. Pero, ¿cuál es la razón para tildar de ficción a la doctrina del contrato social y no más bien al propio orden natural, defendido por los conservadores de modo tan apasionado? El argumento que propone Maistre es el siguiente: nunca ha existido un estado de naturaleza previo a la constitución de las distintas sociedades, como lo supone la doctrina del contrato, sino que el hombre desde un comienzo ha vivido en sociedad y la

\footnotetext{
30 Para un análisis detallado del desarrollo de la idea de libertad, desde la concepción tradicional del libre albedrio, hasta llegar a la libertad ilimitada de ciertas corrientes del liberalismo, y de cómo se relaciona lo anterior con el orden natural, o bien, con su ruptura, $f f$., Widow, J.A., La libertad y sus servidumbres, Santiago de Chile: Ril, 2014.

${ }^{31}$ Véase sobre este concepto, Maistre, J., Estudio sobre la soberanía, Buenos Aires: Dictio, 1980.

32 Para una crítica de la idea del contrato revísese la obra ya mencionada de Maistre, J., Estudio sobre la soberanía.
} 
existencia de hombres que viven al margen de la civilización no prueba nada. Antes bien, refuerza la idea anterior. Este mismo argumento le sirve a Burke 33 para rechazar la doctrina de los derechos humanos, a los que no trepida en calificar de "metafísicos", pues no solo pretenden ser naturales sino también evidentes de suyo, tal como puede leerse en la Declaración de Independencia de Los Estados Unidos de 1776: "Sostenemos por evidentes, por sí mismas, estas verdades: que todos los hombres son creados iguales; que son dotados por su Creador de ciertos derechos inalienables, entre los cuales está la vida, la libertad y la búsqueda de la felicidad" 34 .

Sin embargo, la fuerza del argumento del conservador no está en la reiteración de la vieja idea aristotélica de que el hombre es un ser social por naturaleza, un animal politico, sino en la insistencia de que existe un orden natural, deseado por Dios, su Creador, desde un principio, que permite concluir que los hombres no son todos iguales, no solamente porque se diferencian en cuanto a fuerza y talentos, sino además porque la naturaleza ha dispuesto que el gobierno corresponda a unos pocos mientras que la obediencia y la natural sujeción sea la forzosa obligación de todo el resto ${ }^{35}$. Las consecuencias que se derivan de este último argumento son fáciles de visualizar: en primer lugar, nunca ha habido deliberación por parte de los distintos pueblos en cuanto al tipo de gobierno que mejor pudiese amoldarse a su carácter y temperamento, así como a las leyes que debiesen regir una determinada sociedad en un lugar y un tiempo específicos ${ }^{36}$. Por eso también, desde un comienzo, el legislador ha asumido que no hablaba desde su propia particularidad, sino que, desde la posición de portavoz de la divinidad, la que habla a través suyo, de modo tal que las leyes que deseaba entregarles a los hombres no fuesen vistas como la simple obra humana, fruto tal vez del capricho o de la fantasía, sino siempre como obra de la divinidad, como la expresión máxima de la voluntad de Dios.

Como lo advierte el mismo Maistre: "hay pues que devolver a los espacios imaginarios las ideas de elección y de deliberación en la institución de la sociedad y de la soberanía. Tal operación es obra inmediata de la naturaleza, o, para decirlo mejor, de su autor"37.

${ }^{33}$ Cf., Burke, E., Reflexiones sobre la revolución en Francia, Buenos Aires: Dictio, 1980.

${ }^{34}$ Véase sobre el particular, la Declaración de Independencia de Los Estados Unidos, de 1776, citada en Pacheco, M., Los Derechos Humanos. Documentos Básicos, Santiago de Chile: Editorial Jurídica de Chile, 1997, p. 26.

${ }^{35}$ Cf., Maistre, J., Estudios sobre la soberanía.

36 Ibid.

37 Ibid., p. 20. 
$\mathrm{Y}$, con anterioridad, el mismo autor señalaba lo siguiente a propósito del concepto de pueblo, el cual en la concepción de Rousseau pasaba a designar al soberano: "la palabra pueblo es un término relativo que no tiene sentido separado de la idea de soberanía: porque la idea de pueblo evoca la de una agregación en torno de un centro común, y sin la soberanía no puede haber conjunto, ni unidad política" 38 .

En segundo lugar, de dicho argumento se deriva igualmente que no hay ni puede haber un derecho que no provenga de la divinidad, o bien, que no tenga un origen en la costumbre, en lo que la tradición seguida por los mayores ha tenido a bien disponer. La principal objeción que el conservadurismo formula a la doctrina de los derechos humanos consiste en que semejantes derechos no tienen un origen conocido ni en la costumbre ni tampoco en la revelación divina. Como Burke es quien mejor desarrolla esta última idea, en su alegato dirigido contra la Revolución francesa, conviene cederle la palabra en este punto de la discusión: "el gobierno no se constituye en virtud de derechos naturales, que pueden existir y existen con total independencia de él; y que existen con mucha mayor claridad y con un grado mucho mayor de perfección abstracta; pero esta perfección abstracta es su defecto práctico. Por tener un derecho a todo, se carece de todo. El gobierno es un invento de la sabiduría humana para proveer a las necesidades humanas" 39 .

Dicho de otro modo: no hay ni puede haber un derecho antes del derecho, el cual, en consecuencia, o es fruto de la fantasía de ciertos ideólogos, o simplemente constituye un sinsentido absoluto. De ahí que Burke tilde de metafísicos a estos pretendidos derechos naturales defendidos por los revolucionarios franceses, dado que los únicos derechos a los que todo hombre puede aspirar son a aquellos que la propia sociedad ha tenido a bien concederles, basados en la costumbre o también en la ley divina. Profundizando en su argumentación, Burke hace notar que estos supuestos derechos metafisicos, si bien pueden ser verdaderos para un metafísico que haga abstracción de la existencia de distintas sociedades, todas ellas con su especial cultura y con sus propias leyes, son del todo falsos si se los examina desde el punto de vista de la política, a la que le interesa por sobre todo la dirección de aquellos asuntos prácticos que no pueden ni deben ser dirimidos tomando como base las sutilizas dialécticas sino el cálculo racional. Dado que se pretenden universales, estos derechos aspiran

38 Ibid., pp. 19-20.

39 Burke, E., Reflexiones sobre la revolución en Francia, p. 118.

ARETÉ Revista de Filosofia, v. XXXII, 1, 2020 / ISSN 1016-913X 
a ser válidos en todo momento y lugar, pero es esto último lo que los convierte en poco más que una quimera porque con ello se oculta justamente la imposibilidad de la que arrancan, la que, sin embargo, actúa como una justificación adicional de los mismos. Aunque se trate de una quimera, es forzoso creer en ellos, así como se debe creer en la democracia y en la libertad no importando lo que la razón ni la verdad puedan atestiguar a este respecto: "los supuestos derechos de aquellos teorizadores son todos extremos; y en la medida en que son metafísicamente verdaderos, son moral y políticamente falsos... La razón política es un principio calculador; suma, resta, multiplica y divide, moralmente y no metafísica o matemáticamente, verdaderas unidades morales" ${ }^{40}$.

Lo que se esconde en toda esta discusión es una profunda confusión inducida en parte por el uso ambiguo que se hace de la palabra naturaleza, pues tanto en un caso como en el otro se está apelando a lo mismo: sea a un hipotético estado de naturaleza (Rousseau); sea al orden natural de las cosas (Burke). Eso hace también que la discusión entre liberales y conservadores encierre un gran equívoco. Cuando el conservador ataca la doctrina de los derechos humanos, como lo hace Burke, recurre a la naturaleza, del mismo modo en que lo hace el liberal cuando invoca la existencia de un derecho antes del derecho. Ambos apelan a lo mismo y, por ende, llegan también a lo mismo. Tanto para uno como para otro, la naturaleza es la que decide a fin de cuentas $\mathrm{y}$, por esta misma razón, la impugnación a los derechos humanos que se lleva a cabo desde el pensamiento conservador solo considera la dimensión jurídica de los mismos, pero deja sin tocar las otras dos dimensiones que también es posible distinguir en aquellos: la ético-normativa y la utópica. Más adelante se verá que el neoliberalismo tampoco alcanza a visualizar los aspectos éticonormativos como también utópicos que se derivan de los derechos humanos.

Sin embargo, Burke no se conforma tan solo con denunciar la falsedad de los derechos humanos desde un punto de vista politico y moral, por más verdaderos que estos últimos puedan ser, metafísicamente hablando, sino que él mismo pasa a esbozar lo que puede considerarse como la respuesta conservadora al problema de que es aquello a lo que legitimamente un hombre puede tener derecho: "si la sociedad civil está hecha para beneficio del hombre, todas las ventajas para que está hecha se vuelven su derecho... Los hombres tienen derecho a vivir de acuerdo con dicha regla; tienen derecho a hacer justicia, como entre sus semejantes, sea que estos ejerzan funciones públicas o una

${ }^{40}$ Ibid., p. 121. 
ocupación ordinaria. Tienen derecho a los frutos de su industria, y a los medios de hacer fructifera su industria. Tienen derecho a las adquisiciones de sus progenitores; a la alimentación y progreso de su descendencia; a la educación en vida y al consuelo en la hora de la muerte"41.

De ninguna manera el conservador niega la existencia de ciertos derechos a los que todo hombre puede legitimamente apelar, toda vez que,como señala el mismo autor en el pasaje recién citado, "al haberse constituido la sociedad en beneficio del hombre" las ventajas que de este estado puedan derivarse se vuelven un derecho adquirido, llamado también derecho consuetudinario ${ }^{42}$. La impugnación a la que se ve sometida la doctrina de los derechos humanos por parte del conservador descansa sobre la base de que estos últimos carecen de una especial consagración en una tradición cultural reconocida, o si se prefiere, en la ley divina, como fuente de derecho. Los derechos humanos se pretenden universales, pero dicha universalidad no procede ni de la costumbre ni tampoco de la revelación. Y dado que desde la Revolución francesa se prescinde de la ley divina como fuente de derecho, solo quedan la ley natural y la ley positiva ${ }^{43}$ para sancionar cuando algo es un derecho y cuando no.

Burke prosigue su alegato, llegando a reconocer inclusive una cierta igualdad entre los hombres, en torno a aquello que legítimamente les corresponde como un derecho adquirido y del que todos se beneficiarian por igual: "todo aquello que cada hombre puede hacer individualmente sin violar el derecho ajeno, tiene derecho a hacerlo por sí mismo; y tiene derecho a una buena porción de lo que toda la sociedad, con todas sus combinaciones de habilidad y fuerza, puede hacer en su favor" 44 .

Así, por ejemplo, cada hombre tiene derecho a emprender un negocio siempre que se trate de algo lícito y que no se encuentre reñido con la ley, del que puede legitimamente beneficiarse, beneficiando igualmente a sus más cercanos. En este último punto, la posición del conservador no disiente en demasía de la postura de cualquier liberal porque en ambos casos se trata del derecho que cada hombre tiene de usufructuar de su propiedad como mejor le plazca.

Tampoco habría discrepancia en cuanto a la desigualdad que se desprende de lo anterior: "en esta coparticipación todos los hombres tienen iguales dere-

\footnotetext{
41 Ibid., p. 117.

42 Este derecho consuetudinario es aquel derecho consagrado por la costumbre como otra fuente más del derecho, junto al derecho natural y al derecho positivo.

${ }^{43}$ Se entiende por la ley natural aquella ley no escrita, cuyo fundamento es la propia naturaleza humana, mientras que la ley positiva designa la norma escrita, fijada a través de una constitución

${ }^{44}$ Burke, E., Reflexiones sobre la revolución en Francia, p. 117.
} 
chos; pero no a cosas iguales" 45 . Los hombres tienen iguales derechos, pero eso en ningún caso los hace iguales en cuanto a la fortuna que cada uno de ellos es capaz de proveerse. La desigualdad de riqueza trae aparejada a su vez una desigualdad en el acceso y ejercicio del poder: "quien no tiene más que una participación de cinco chelines, tiene tan buen derecho como el que tiene aquel que posee quinientas libras a su mayor proporción en la sociedad colectiva. Pero no tiene derecho a un dividendo igual del producto del capital social"46.

Este último pasaje deja en evidencia la desigualdad que existe entre los hombres en cuanto a la participación que le corresponde a cada uno en el producto que se desprende del capital social.

Pero el autor no se conforma con señalar esto último y agrega algo más, que viene como a confirmar el acuerdo fundamental que hay entre conservadores y liberales en lo que se refiere a la "desigualdad natural" existente entre los hombres: "y por lo que respecta a la participación en el poder, la autoridad y la dirección, que cada individuo debería tener en la administración del Estado, debo negar que se halle entre los derechos inmediatos y originarios del hombre en la sociedad civil; pues estoy considerando al hombre civil en sociedad, y a ningún otro. Eso es cosa que se debe determinar por convención"47.

Los hombres no son iguales ni en lo que se refiere a la extensión de su fortuna ni tampoco en aquello que guarda relación con el ejercicio del poder. La sola idea de una igualdad en cuanto a derechos no pasa de ser un puro desiderátum. Para el conservador, la desigualdad se justifica por la existencia de un orden natural, no creado por el hombre, que establece con claridad quienes han de mandar y quienes habrán de obedecer. De ninguna manera la invocación que hace el conservador del orden natural debiese ser vista como algo injusto, dado que semejante ordenamiento no obedece a un capricho de los hombres sino a una disposición de la propia naturaleza, o si se prefiere, del autor de esta: Dios.

El mismo Burke, comentando críticamente la tesis de Rousseau referida al contrato social, afirmará que cualquier sociedad es, en efecto, un contrato, pero que se establece entre los vivos, los muertos y los que están por nacer. Por eso, ningún pueblo tiene derecho a destruir por un loco capricho la obra de las generaciones pasadas, a la que todo hombre se encuentra sujeto por su nacimiento, por la adscripción a una cultura así como por la educación: "la

\footnotetext{
45 Ibid.

46 Ibid.

47 Ibid., pp. 117-118.
} 
sociedad es en verdad un contrato... pero el Estado no debe ser considerado como nada mejor que un acuerdo de asociación para el negocio de la pimienta y el café, el algodón o el tabaco, o algún otro bajo menester, que se concluye con vista a pequeños intereses pasajeros, y se disuelve según el capricho de las partes. Debe mirárselo con otra reverencia; porque no es una asociación en cosas que sirven únicamente para la grosera existencia animal, de naturaleza temporaria y perecedera... Como sus fines no se pueden lograr en muchas generaciones, es una sociedad no solo entre vivos, sino entre los vivos, los muertos y los que están por nacer"48.

$\mathrm{El}$ autor agrega con tono solemne: "cada contrato de cada Estado particular no es más que una cláusula en el gran contrato primitivo de la sociedad eterna, que vincula las naturalezas más bajas con las más altas, conectando el mundo visible con el invisible, según pacto fijo sancionado por el juramento inviolable que mantiene a todas las naturalezas fisicas y morales, a cada una en su debido lugar"49.

La discusión entre conservadores y liberales se da en el contexto de la Revolución francesa. Quienes defienden al viejo régimen recibirán el nombre de conservadores, mientras que aquellos que aplauden la empresa revolucionaria se identificarán a sí mismos como liberales. Sin embargo, ambos se verán obligados a unirse ante la aparición de un nuevo adversario, que se opondrá por igual tanto a liberales como a conservadores: el socialismo ${ }^{50}$.

\section{Critica de los derechos humanos desde el neoliberalismo}

En este trabajo se entenderá por neoliberalismo una doctrina específicamente económica que concibe al mercado como un orden natural, tan perfecto en apariencia que pareciera no haber sido creado por el hombre, sino más bien por una inteligencia superior ${ }^{51}$. El primero en hablar de neoliberalismo fue el economista alemán Alexander Rüstow en 1938, en el contexto de un coloquio convocado en París, con el nombre de Coloquio Walter Lippmann, a fin de defender el sistema de precios, la libre empresa y la necesidad de un Estado imparcial. Según Rüstow, el término acuñado por él designaba un tipo

\footnotetext{
48 Ibid., pp. 166-167.

49 Ibid., p. 167.

${ }^{50}$ Véase sobre este particular, Mahoney, D., Fundamentos conservadores del orden liberal, Santiago de Chile: Instituto de Estudios sobre la Sociedad, 2015.

${ }^{51}$ Cf., Hayek, F.A., Camino de servidumbre, San José de Costa Rica: Universidad Autónoma de Centro América, 1986.
} 
de "liberalismo remozado" que, retomando las posiciones más tradicionales defendidas por el liberalismo clásico, se pronunciaba abiertamente en contra de cualquier intervencionismo estatal en la marcha de la economía. Con todo, pese a sus orígenes en la economía, el neoliberalismo debe ser visto como una doctrina de alcances globales, que trasciende la esfera económica propiamente tal, afectando a otras esferas como las del derecho, la educación o la salud por mencionar solo algunas de esas esferas que se ven afectadas por el modo en que el neoliberalismo concibe la relación entre el Estado, las personas y el resto de la sociedad civili52.

Dos preguntas surgen de inmediato, a las que se tratará de dar una debida respuesta en lo que sigue del presente trabajo: ¿por qué surge el neoliberalismo? ¿Es adecuado y conveniente seguir hablando de un neoliberalismo cuando muchos autores vinculados con esta doctrina se resisten a ser tildados como neoliberales prefiriendo llamarse simplemente liberales?53.

Los orígenes de la doctrina neoliberal se encuentran en el tipo de sociedad surgida después de la Segunda Guerra Mundial (1939-1945), caracterizada por lo que se ha solido llamar como un "liberalismo embridado", concepto que sirve para designar a aquellas sociedades en donde los mercados se encuentran fuertemente regulados, con una amplia participación de los sindicatos y un Estado especialmente preocupado por garantizar el acceso de todos los ciudadanos a los bienes sociales, como lo son la educación y la salud ${ }^{54}$. A esa forma de Estado se la conoce también como Estado de bienestar, y el contexto histórico en el que surge se relaciona directamente con la necesidad de reconstruir Europa después de la gran guerra, por lo que el consenso mayoritario entre los distintos gobiernos en ese momento era el de contar con un Estado fuerte, capaz de liderar la reconstrucción garantizando a su vez el máximo de bienestar social para la población ${ }^{55}$.

Sin embargo, algunos intelectuales comenzaron a mirar con recelo el surgimiento de estas sociedades basadas en la presencia de Estados fuertes y mercados sobrerregulados, dado que con lo anterior se estaría colocando en cuestión algunas de las conquistas fundamentales del liberalismo clásico, como el libre emprendimiento y la propiedad privada ${ }^{56}$. Es así que, en 1947, apenas

52 Cf., Contreras, M. A., Crítica a la razón neoliberal, México: Akal, 2015.

${ }^{5}$ Cf., Benegas, A., Socialismo de mercado. Ensayo sobre un paradigma posmoderno, Rosario: Ameghino Editora, 1997; Kaiser, A. y G. Álvarez, El engaño populista, Barcelona: Deusto, 2016.

${ }^{4}$ Cf., Harvey, D., Breve historia del neoliberalismo, México: Akal, 2015.

55 Ibid.

${ }^{56} C f$., Contreras, M.A., Crítica a la razón neoliberal. 
dos años después de concluida la guerra, se crea la Mont Pelerin Society, bajo la dirección del economista austriaco Friedrich von Hayek, tomando su nombre del balneario suizo donde se realizaron las primeras reuniones del grupo. Entre sus integrantes se encontraban el economista estadounidense Milton Friedman, el también economista Ludwig von Mises, y el filósofo Karl Popper, entre otros. En su declaración de principios, el grupo sostiene que los valores fundamentales de la civilización occidental, inspirados en el liberalismo y en la herencia judeo-cristiana, están amenazados, por la acción de algunas ideas que tienden a cuestionar el rol del mercado y a promover la intromisión de los gobiernos en esferas que no son de su incumbencia.

En la declaración, se resalta que la conquista más preciada del hombre occidental, la libertad, se encuentra sometida a un fuerte ataque desde diversos frentes: "sobre grandes extensiones de la superficie del planeta las condiciones esenciales de la dignidad y de la libertad humana ya han desaparecido. En otras, están bajo constante amenaza ante el desarrollo de las tendencias políticas actuales... Hasta la más preciada posesión del hombre occidental, su libertad de pensamiento y de expresión, está amenazada por el despliegue de credos que, reclamando el privilegio de la tolerancia cuando están en situación de minoría, procuran solamente establecer una posición de poder desde la cual suprimir y obliterar todas las perspectivas que no sean las suyas" 57 .

Una vez aclarado lo concerniente al origen histórico de esta doctrina, debe determinarse cuáles son sus fundamentos, qué es lo que tiene en común y en qué se diferencia de otras formas de liberalismo. El punto de partida del neoliberalismo es el mismo que el de otras corrientes que se declaran liberales. Existe un orden natural que no ha sido hecho por los hombres, sino que emerge espontáneamente -el orden del mercado ${ }^{58}-\mathrm{y}$ que debe ser respetado si lo que las distintas sociedades pretenden es avanzar en un régimen de libertades, amparado en el respeto irrestricto a la ley y a la existencia de un Estado de derecho. Este orden natural permite que los seres humanos satisfagan, por una parte, sus inclinaciones más egoístas y, por la otra, a través de lo anterior, promueve el bienestar general de la sociedad, siendo irrelevante que lo que cada uno de los seres humanos busca en realidad sea su propio beneficio y

\footnotetext{
${ }^{57}$ Declaración inicial de principios de la Mont Pelerin Society, citada en: Harvey, D., Breve historia del neoliberalismo, p. 26.

${ }^{58}$ Hayek le otorga el nombre de "catalaxia" a este orden que brota de modo espontáneo a partir del funcionamiento del mercado, coincidiendo en parte con lo señalado por Adam Smith, con la mano invisible. Cf., Los principios de un orden social liberal, Santiago de Chile: Centro de Estudios Públicos, 1981.
} 
no el de los demás. Partiendo de los presupuestos teóricos de Adam Smith, en especial de la famosa "mano invisible" del mercado, la antropología del neoliberalismo es idéntica a la del liberalismo clásico, en cuanto a que lo que mueve al hombre es el egoísmo, la ambición desenfrenada, la glotonería, así como el resto de tendencias antisociales que hacen que cada ser humano solo piense en sí mismo, sin importarle en absoluto lo que suceda al resto de la humanidad.

Como reconoce abiertamente el mismo Adam Smith: "no es la benevolencia del carnicero, del cervecero o del panadero la que nos procura el alimento, sino la consideración de su propio interés. No invocamos sus sentimientos humanitarios sino su egoísmo; ni les hablamos de nuestras necesidades, sino de sus ventajas" 59 .

Partiendo de lo anterior, el neoliberalismo concibe la sociedad como un orden que brota espontáneamente, que no obedece a ningún cálculo premeditado ni tampoco se origina a partir de un contrato originario, tal como pensaba el liberalismo clásico. Este modelo explicativo recibe el nombre de "modelo tipo mano invisible", similar al de Adam Smith, que se contrapone abiertamente a la antigua concepción del contrato social ${ }^{60}$. En esta doctrina, dado que tanto la sociedad como el Estado surgen espontáneamente como la consecuencia no buscada de las interacciones que se dan entre los seres humanos, el mecanismo que se encarga de mantener el equilibrio entre los intereses particulares que persiguen los distintos individuos y el interés general de la propia sociedad es el mercado, a través del sistema de precios. El rol que cumple el sistema de precios es el de facilitar la toma de decisiones por parte de las personas, dada la información fragmentaria que cada una de ellas maneja, haciendo posible que esta información fluya combinándose con el resto de la información que manejan las demás personas. Esto último permite determinar con precisión cuáles son las necesidades de las personas y cómo satisfacerlas oportunamente, a diferencia, por ejemplo, de lo que acontecía en el socialismo real, en donde la ausencia de este mecanismo hacía imposible que se pudiese determinar con exactitud tanto las necesidades como la mejor manera de poder satisfacer estas mismas ${ }^{61}$.

La concepción que el neoliberalismo tiene de los derechos humanos parece coincidir igualmente con aquella que en su momento promovió el liberalismo clásico. En efecto: "los individuos tienen derechos, y hay cosas que ninguna

\footnotetext{
59 Smith, A., Investigación sobre la naturaleza y causas de la riqueza de las naciones, México: Fondo de Cultura Económica, 2012, p. 17

60 Cf., Nozick, R., Anarquí, Estado y utopía, 2012.

61 Cf., Friedman, M., Libertad de elegir, Mises, L., Liberalismo. La tradición clásica.
} 
persona o grupo puede hacerles sin violar los derechos"62. La primera consecuencia que se deriva de todo esto es que los derechos únicamente pueden ser individuales y nunca sociales, pues solamente los individuos existen, no así la "sociedad", el "Estado", o alguna otra especie de entelequia que se le parezca. A esta concepción de los derechos, según la cual solamente "...existen individuos particulares con derechos particulares a cosas particulares" 63 , se le conoce con el nombre de nominalismo jurídico. La segunda consecuencia que se saca de aquí es la de que los hombres se relacionan entre sí como si se tratase de átomos, aleatoriamente, persiguiendo únicamente la satisfacción de sus necesidades egoístas, de modo tal que la sociedad no tiene más realidad que aquella que le confiere el contrato, en opinión del viejo liberalismo, o como el producto no intencionado de las propias interacciones humanas, en opinión de los neoliberales, quienes siguen a Adam Smith en este último punto.

Puesto que la sociedad y el Estado surgen, como la consecuencia no buscada, de las interacciones que se dan entre las personas, no hay nada más obvio, en apariencia, que concluir que la sociedad se encuentra constituida por verdaderos átomos sociales que solo se mantienen unidos por la acción del Estado, como era la opinión del liberalismo clásico, o del mercado, como corrige el neoliberalismo. No obstante lo anterior, la conclusión es una sola y se impone por sí misma: la sociedad civil no existe. A esto habría que agregar que cualquier otro colectivo en el que se piense, como podrian serlo las comunidades constituidas en torno a la existencia de ciertos lazos, tales como la pertenencia a una etnia, tampoco existen. Existen solamente las personas, y frente a ellas se erige el Estado con el propósito manifiesto de cautelar el derecho de propiedad, sin el cual no puede haber libertad.

Dado que se pierde la dimensión del contrato, porque desaparece cualquier asomo de un colectivo, el mercado se transforma en el punto de encuentro donde coinciden las distintas personas. Frente a lo anterior, la idea fundamental que tenían en mente los teóricos del neoliberalismo es la siguiente: en un intercambio voluntario, en el cual quienes participan lo hacen voluntariamente, no de un modo forzado, el beneficio es mutuo. No es necesaria la coacción cuando quienes se encuentran lo hacen de modo voluntario y no forzado. Por eso, la justificación del Estado se reduce a tres cuestiones fundamentales:

A) La defensa de las fronteras,

B) La defensa de la propiedad y

${ }^{62}$ Nozick, R., Anarquía, Estado y utopia, p. 7.

63 Ibid., p. 238. 
C) Atender aquellas cuestiones que tradicionalmente se consideraban que quedaban al margen de la acción de los privados (por ejemplo, la educación o la salud).

Los neoliberales aceptan la primera y la segunda cuestión, pero cuestionan el sentido y el alcance de la tercera. Puesto que el mercado es el lugar donde se encuentran las personas, parece obvio que también aquellas áreas que quedaban fuera de la acción de los privados, se gobiernen en conformidad con las lógicas del mercado. Por su parte, Hayek $^{64}$ establece que los principios que deben gobernar una sociedad libre se resumen en la libertad, la justicia y la paz. La libertad se entiende como la libertad de comerciar dentro del mercado, la cual no debería tener límites de ninguna clase. La justicia comprende el respeto y la obediencia irrestricta al marco legal establecido dentro de un Estado de derecho. Por último, la paz se deriva del respeto a las leyes, en especial de aquellas que apuntan a preservar la propiedad, asegurando el ejercicio pleno de la libertad.

Desde el punto de vista de la concepción neoliberal, el individualismo es un principio que atraviesa esta doctrina, permeándola en distintas direcciones. Para Popper, por ejemplo, el individualismo desborda el aspecto antropológico alcanzando al ámbito epistemológico y también metodológico. En su crítica del historicismo, Popper señala, a propósito del problema del método que afecta a las ciencias sociales: "Se halla ampliamente difundida la creencia de que toda actitud verdaderamente científica o filosófica, como así toda comprensión más profunda de la vida social en general, debe basarse en la contemplación e interpretación de la historia humana. En tanto que el hombre corriente acepta sin consideraciones ulteriores su modo de vida y la importancia de su experiencia personal y pequeñas luchas cotidianas, se suele decir que el investigador $o$ filósofo social debe examinar las cosas desde un plano más elevado"65.

Popper se apresura a invertir el argumento anterior, al que tilda de "totalitario", pasando a afirmar que el punto de partida de las ciencias sociales deben ser las personas, sus creencias y sus motivaciones. Por su parte, Hayek agrega lo siguiente, confirmando su total apoyo a los planteamientos esbozados por Popper: "Individualismo es hoy una palabra mal vista, y ha llegado a asociarse con egotismo y egoísmo"66. En oposición a esta creencia, Hayek sostiene que el individualismo que él defiende nada tiene que ver con el egoísmo, sino que

${ }^{64}$ Cf., Hayek, F.A., Los principios de un orden social liberal.

${ }^{65}$ Popper, K., La sociedad abierta y sus enemigos. Barcelona: Paidós, 1981, p. 23.

${ }^{66}$ Hayek, F.A., Camino de servidumbre, p. 41. 
representa la sintesis del legado cultural grecolatino, por una parte, y de la herencia judeocristiana, por la otra. Además, este legado alcanza su perfección en el Renacimiento: "ahora bien, los rasgos esenciales de aquel individualismo... son: el respeto por el hombre individual qua hombre, es decir, el reconocimiento de sus propias opiniones y gustos como supremos en su propia esfera, por mucho que se estreche esta, y la creencia en que es deseable que los hombres puedan desarrollar sus propias dotes e inclinaciones individuales"67.

El individualismo defendido por los teóricos del neoliberalismo conduce a ciertas consecuencias prácticas en lo que se refiere a los derechos humanos. La primera de ellas es la desaparición de toda noción de derecho, dado que para comenzar a hablar de algo entendido como un "derecho" se hace necesario considerar la dimensión social del mismo. Sin embargo, a juicio del neoliberalismo, la sociedad civil no existe, por lo que desaparece la dimensión pública y, con ella, se pierde la razón de ser del derecho, puesto que ahora es el mercado el que regula las interacciones entre los distintos individuos y no una especie de contrato inexistente (a diferencia del liberalismo clásico). La segunda consecuencia es que con el neoliberalismo el derecho se ve desplazado por un enfoque basado en las necesidades, tal como estas emergen del mercado, por lo que se pierde completamente la noción de justicia, asociada a los derechos humanos, y su exigibilidad.

Lo anterior parece contradictorio, sobre todo si se toma en cuenta el punto de partida del que arranca el pensamiento neoliberal, dado que es el mismo del que partió en su momento el liberalismo clásico. Solo existen los individuos, los cuales poseen derechos que ningún Estado debe violar, emprendiendo ciertas acciones que supongan un atentado contra estos últimos. Por eso, el único Estado que se puede justificar es el llamado "Estado mínimo", que se limita a garantizar la vida y la propiedad de las personas ${ }^{68}$. También Hayek y Popper reivindican los derechos naturales, ante todo en la defensa que ambos hacen de lo que Popper denomina la sociedad abierta ${ }^{69}$.

Parece, pues, que el neoliberalismo sí posee un enfoque de derecho, aunque restringido a los derechos individuales ${ }^{70}$. Pero lo anterior dista de estar claro porque el problema que presenta la teoría neoliberal es que lo reduce todo al plano individual. La sociedad civil desaparece y, con esto, se pierde el

67 Ibid., p. 41.

${ }^{68}$ Cf., Nozick, R., Anarquí, Estado y utopía.

${ }^{69}$ Cf., Popper, K., La sociedad abierta y sus enemigos.

${ }^{70} \mathrm{Cf}$., Hayek, F. A., Camino de servidumbre. 
contrato y también cualquier sentido que todavía pudiese caberle al derecho. $\mathrm{Si}$ no hay ningún colectivo, se pierde de vista la función social que le corresponde al derecho, por lo que en estricto rigor solo habría necesidades que el mercado debe satisfacer, pero no derechos, perdiéndose igualmente la dimensión de justicia sin la cual no se puede apelar a la exigibilidad tan propia del derecho.

Como Hayek es quien desarrolla con mayor profundidad los alcances de esta filosofia social, conviene cederle la palabra en este punto, a fin de profundizar en las consecuencias que se derivan de ella. La concepción neoliberal rechaza de plano la noción de justicia social, considerándola poco menos que un oximoron ${ }^{71}$. La argumentación seguida por Hayek es la siguiente: en una sociedad libre, cada persona tiene derecho a elegir libremente el trabajo al que desea consagrarse y el tipo de vida que quiere seguir y los esfuerzos que debe realizar para alcanzar dichas metas son, por lo tanto, de entera responsabilidad suya y de nadie más. Del mismo modo, las consecuencias afortunadas o desafortunadas que se deriven de lo anterior recaen por completo sobre las elecciones individuales adoptadas por cada persona en el ejercicio de su libertad $^{72}$. Este último planteamiento conduce a Hayek a rechazar del modo más vehemente cualquier clase de política económica centrada en la justicia distributiva, conocida también con el nombre de justicia social, como las propiciadas desde el socialismo.

Como el mismo Hayek lo hacer notar, al resumir su pensamiento, "la libre elección de ocupación y la libre elección de lo que quiere producir o de qué servicios quiere prestar cada uno, son irreconciliables con la justicia distributiva"73.

Desde Aristóteles se establece una clara distinción entre la "justicia conmutativa" y la "justicia distributiva". El Estagirita pensaba que la primera forma de justicia correspondía al cumplimiento de la ley, mientras que la segunda apuntaba a una dimensión mucho más profunda, donde de lo que se trataba realmente era de retribuir a cada ciudadano en conformidad con aquello de lo que se ha hecho merecedor ${ }^{74}$. Hayek, por su parte, entiende que en una sociedad libre solo tiene cabida la primera forma de justicia, mas no la segunda, que caracterizaria a aquellas sociedades en donde ha desparecido cualquier asomo de libertad personal. Para respaldar su posición, Hayek define la justicia conmutativa como aquella en la que el individuo es premiado o castigado

\footnotetext{
${ }^{71}$ Cf., Moya, J., La ideología del esfuerzo, Madrid: La Catarata, 2014.

2 f., Hayek, F. A., Camino de libertad.

73 Ibid., p. 155.

74 Cf., Aristóteles, Ética a Nicómaco, Madrid: Centro de Estudios Políticos y Constitucionales, 2002.
} 
dependiendo de la calidad del servicio que presta, sin importar si ese servicio le significó un esfuerzo mayor o menor, y también independientemente de si algunos se van a beneficiar más que otros por los servicios ofrecidos, aunque estos sean realizados bajo condiciones más bien parecida (como acontece con las brechas salariales existentes entre hombres y mujeres, inclusive cuando se trata de un mismo trabajo). Entiende, por el contrario, la justicia distributiva como aquella en la que una persona es premiada o sancionada no en virtud del mérito de lo que ha hecho, sino de la opinión que de aquello se forman las demás personas.

Hayek sintetiza su pensamiento del siguiente modo: "Los resultados de una remuneración tal, que paga de acuerdo al valor del producto, aparecen como altamente injustos desde el punto de vista de la justicia distributiva... Que el especulador que ha adivinado correctamente pueda ganar una fortuna en pocas horas, mientras que los esfuerzos de toda una vida de un inventor, que ha sido anticipado por otro en cosa de días, permanecen sin remuneración, o que el duro trabajo de un campesino arraigado a su tierra le dé apenas para mantenerlo en pie, mientras que un hombre que le gusta escribir historias de detectives pueda ganar lo suficiente como para llevar una vida lujosa, parecerá injusto para la mayoría de la gente... Si el problema fuera una cuestión de si la fe o algún poder omnisciente y omnipotente debe recompensar a las personas, de acuerdo con los principios de la justicia conmutativa o bien de justicia distributiva, probablemente todos nosotros elegiremos los últimos"75.

Para un liberal como Hayek, ningún derecho es más importante que la libertad, no existiendo otra limitación para el ejercicio soberano de esta que la vulneración de las libertades ajenas, de otra persona. Por eso, su crítica de la justicia social cala tan hondo si se la compara con el rechazo conservador a los derechos humanos, pues separados estos de cualquier dimensión que involucre la justicia, prácticamente desaparecen, perdiendo toda razón de ser.

Con el neoliberalismo se pierde, casi del todo, la dimensión jurídica de los derechos humanos y se cuestiona además el carácter ético-normativo de estos últimos, clausurándose también el horizonte utópico que necesariamente debe permear a todo enfoque de derecho que se precie de tal, debido a que se niega la justicia, con lo que se desecha la exigibilidad propia del derecho. Pero, ¿cuál es la razón fundamental para que se produzca aquello? La respuesta que dan algunos autores atiende mucho más a la epistemología que a la ontología

${ }^{75}$ Hayek, F.A., Camino de libertad, pp. 154-155.

ARETÉ Revista de Filosofía, v. XXXII, 1, 2020 / ISSN 1016-913X 
del neoliberalismo ${ }^{76}$. Debe recordarse que, para un autor como Popper, el individualismo adquiere el rango de un principio, con consecuencias tanto en el plano epistemológico como también metodológico. Si se parte de la base de que las personas actúan para satisfacer una serie de necesidades, contando para ello con una cantidad limitada de recursos, entonces la conclusión más obvia que resulta de lo anterior es que se hace necesario optimizar los recursos, priorizando unas necesidades por sobre otras. El mercado ha demostrado ser hasta ahora la mejor instancia para decidir qué cosas es necesario producir y en qué cantidades, a fin de satisfacer aquellas necesidades que se consideran fundamentales. Es así que, tal como lo hace notar Mises ${ }^{77}$, la misma acción humana se encuentra gobernada por leyes naturales, las que, debido al desconocimiento o, lo que es peor, a la ignorancia propiciada por algunas ideologías como el marxismo, en cuanto a cómo estas leyes actúan, conduce a las sociedades humanas y a sus respectivos gobiernos a toda clase de desastres. Se entiende la acción humana ${ }^{78}$ como una actividad intencionada y orientada a perseguir ciertos fines, la cual estaría gobernada por leyes, invisibles para la mayoría de las personas, pero que la teoría debe colocar al descubierto con el fin de orientar de mejor modo las políticas desplegadas por los gobiernos. La crítica realizada por Hayek a la noción de justicia distributiva debe entenderse siempre bajo este contexto.

A fin de cuentas, para un neoliberal, por mucha simpatía que despierten en las personas ciertas cosas a las que se quiere convertir en derecho, como pueden serlo la educación o la salud, no son nada más que privilegios que un grupo pretende hacer valer en contra de otro o lo que es igual, a costa de la sociedad. Por eso, en estricto rigor, solo debería hablarse de necesidades, no de derechos, que serían satisfechas por intermedio del mercado y en lo posible con prescindencia del Estado.

Teniendo en cuenta lo anterior, es posible afirmar que la posición adoptada por el neoliberalismo es mucho más radical que la postura conservadora en cuanto a su rechazo a los derechos humanos. No solo se conforma con criticar estos en el plano jurídico, sino que inclusive llega a negar hasta su misma existencia. Tal como en el caso del conservadurismo, la crítica neoliberal atiende de preferencia a la primera dimensión y solo ocasionalmente a la segunda,

\footnotetext{
76 Cf., Contreras, M.A., Crítica a la razón neoliberal.

7 Cf., Mises, L., La acción humana.

78 Mises llama "praxeología" a la disciplina que estudia la acción humana, llegando a postularla como el fundamento epistemológico de la economía, en la obra del mismo nombre.
} 
pero en el neoliberalismo hay un elemento que no se encuentra presente en el pensamiento conservador: la negación misma del derecho. Dado que para que exista el derecho se hace necesaria la existencia previa de la sociedad, y puesto que el pensamiento neoliberal niega lo anterior, la conclusión que se impone es que con lo anterior se niega igualmente el derecho porque se niega de plano cualquier apelación a la justicia. Con esto último, desaparece también el horizonte utópico de la discusión en torno a los derechos humanos, pues para que lo anterior fuese todavía posible, debería existir la posibilidad de apelar a la justicia, pero al ser negada esta última no hay ninguna razón para seguir hablando de aquellos.

Se justifica igualmente hablar de un neoliberalismo dadas las características que presenta esta corriente, tanto desde un punto de vista epistemológico como también metodológico, lo que permite distinguirla además de otras posiciones cercanas al liberalismo clásico. Si bien es cierto que autores como Hayek, nunca se reconocieron abiertamente como neoliberales, llamándose solo liberales, las distancias que separan a estos autores de otros que igualmente se adscriben a posiciones afines al liberalismo, como Raymond Aron, por ejemplo, son demasiado evidentes para ignorarlas.

\section{Conclusión}

En este trabajo se examinaron tres corrientes -la liberal, la conservadora y la neoliberal- atendiendo de preferencia a la critica que se perfila en ellas acerca de los derechos humanos, en cuanto posibilidad. En primer lugar, se examinó el liberalismo clásico, dándose cuenta de sus antecedentes históricos y filosóficos; igualmente se consideraron las distintas tendencias que dicen inspirarse en este, como el liberalismo conservador y el liberalismo social. A continuación, se analizó el pensamiento conservador, deteniéndose de modo especial en la figura de Edmund Burke, por ser el primero que propone una crítica más o menos sistemática de los derechos humanos. Finalmente se procedió a examinar el neoliberalismo, dándose cuenta de sus antecedentes históricos, sus principales representantes y las diferencias que lo separan tanto del liberalismo clásico como también del conservadurismo.

Durante el transcurso del presente trabajo, se pudo constatar que, en las tres tradiciones filosóficas examinadas, el tenor principal de sus críticas a los derechos humanos giraba exclusivamente en torno a la primera dimensión de estos últimos, aludiéndose de un modo ocasional, a la segunda dimensión, e ignorándose por completo la tercera. 
Sin embargo, en el caso del neoliberalismo, surgió un elemento nuevo que no estaba contemplado en las otras dos corrientes que se examinaron en este trabajo. Dicho elemento apunta a la absoluta imposibilidad de fundar cualquier enfoque de derecho, basado en el neoliberalismo, dada la negación rotunda que hay en este, de la pretensión de justicia, sin la cual el derecho carece de sentido. Si bien es cierto que los autores neoliberales intentan distinguir entre la justicia conmutativa y la justicia distributiva, rechazando solamente la segunda, el acendrado individualismo que preside todos sus análisis hace imposible que se pueda levantar una propuesta creíble, desde esta filosofia, sobre el derecho. Si solo existen los individuos, no mediando entre estos ninguno de los cuerpos intermedios, como pueden serlo las familias, u otras asociaciones de carácter colectivo, sino únicamente el mercado, desaparece en la práctica cualquier sentido que todavía conserve el derecho. Solo quedan las necesidades, y no parece haber nada mejor que el mercado para gestionar estas, dado el carácter limitado de los recursos con que se cuenta para satisfacer todas y cada una de las demandas.

Recibido: 30/01/2018

Aceptado: 27/12/2018

\section{Bibliografia}

Aristóteles, Ética a Nicómaco, Madrid: Centro de Estudios políticos y constitucionales, 2002.

Barrantes, M.P., El fundamento ideológico de los derechos humanos. Crítica ideológica al discurso de la Corte Interamericana de Derechos Humanos, Tesis (Derecho), San José de Costa Rica: Universidad de San José de Costa Rica, 2008.

Bariffi, F.J., "Negación de los Derechos Humanos: el pensamiento conservador de Edmund Burke", en: Revista Telemática de Filosofía del Derecho, v. XI (2003), pp. 265-278.

Benegas, A., Socialismo de mercado. Ensayo sobre un paradigma posmoderno, Rosario: Ameghino Editora, 1997.

Bobbio, N., Liberalismo y democracia, México: Fondo de Cultura Económica, 2010.

Burke, E., Reflexiones sobre la revolución en Francia, Buenos Aires: Ediciones Dictio, 1980.

Contreras, M. A., Crítica a la razón neoliberal, México: Akal, 2015.

Friedman, M., Libertad de elegir, Buenos Aires: Orbis, 1983.

García, C., La revolución mundial del capitalismo, Buenos Aires: El Ateneo, 1988.

Harvey, D., Breve historia del neoliberalismo, México: Akal, 2015.

Hayek, F. A., Los principios de un orden social liberal, Santiago de Chile: Centro de Estudios Públicos, 1981. 
Hayek, F. A., Camino de libertad, Santiago de Chile: Centro de Estudios Públicos, 1981.

Hayek, F. A., Camino de servidumbre. San José de Costa Rica: Universidad Autónoma de Centro América, 1986.

Hobbes. T., Leviatán, México: Fondo de Cultura Económica, 2010.

Hobsbawm, E., La era de la revolución, México: Fondo de Cultura Económica, 2012.

Kaiser, A., La tirania de la igualdad, Santiago de Chile: El Mercurio Ediciones, 2015.

Kaiser, A. y G. Álvarez, El engaño populista, Barcelona: Deusto, 2016.

Larraín, J., ¿América Latina moderna? Globalización e identidad, Santiago de Chile: Lom Editores, 2005.

Locke, J., Segundo tratado del gobierno civil, Madrid: Aguilar, 2010.

Locke, J., Ensayo y carta sobre la tolerancia, Madrid: Alianza Editorial, 2011.

Mahoney, D., Fundamentos conservadores del orden liberal, Santiago de Chile: Instituto de Estudios de la Sociedad (IES), 2015.

Maistre, J., Estudio sobre la soberanía, Buenos Aires: Ediciones Dictio, 1980.

Mill, J.St., Sobre la libertad; El utilitarismo, Buenos Aires: Orbis, 1980.

Mises, L., La acción humana, Madrid: Unión Editorial S.A., 1986.

Mises, L., Liberalismo. La tradición clásica, Madrid: Unión Editorial S.A., 2011.

Moya, J., La ideología del esfuerzo, Madrid: La Catarata, 2014.

Nozick, R., Anarquía, Estado y utopía, México: Fondo de Cultura Económica, 2012.

Pacheco, M., Los Derechos Humanos. Documentos Básicos, Santiago de Chile: Editorial Jurídica de Chile, 1997.

Popper, K., La sociedad abierta y sus enemigos, Barcelona: Paidós, 1981.

Rousseau, J.J., El contrato social, Buenos Aires: Editorial Gradifco, 2007.

Smith, A., Investigación sobre la naturaleza y causas de la riqueza de las naciones, México: Fondo de Cultura Económica, 2012.

Widow, J. A., La libertad y sus servidumbres, Santiago de Chile: Ril Editores, 2014. 